\title{
IP CAMERA SURVEILLANCE SYSTEM USING ANDROID APPLICATION BASED ON ARDUINO
}

\author{
* Belinda Ayuningtyas ${ }^{1}$, Syaeful Ilman ${ }^{2}$ \\ 1,2 Fakultas Teknik dan Informatika, Program Studi Teknik Elektro, Universitas Dian Nusantara, Jakarta, Indonesia
}

*Email Korespondensi:

belinda.ayuningtyas@undira.ac.id

\section{ARTIKEL INFORMASI}

Diterima:

3 March 2021

Direvisi:

15 April 2021

Dipublikasi:

16 Mei 2021

\begin{abstract}
ABSTRAK
Keamanan menjadi fokus utama bagi setiap orang, terutama bagi mereka yang memiliki barang berharga. Kamera pengintai merupakan salah satu cara untuk mencegah terjadinya pencurian. Sistem pengawasan telah dirancang dengan menggunakan IP kamera dengan fitur Motion Detection di dalamnya. Fungsi kamera IP adalah untuk mendeteksi dan menangkap gambar dari setiap gerakan dengan menggunakan fiturnya dan mengirimkan snapshot ke situs pengguna melalui FTP (File Transfer Protocol). Selain itu, sensor PIR (Passive InfraRed) yang digunakan sebagai motiondetector akan dihubungkan ke mikrokontroler Arduino uno dan ethernet shield. Sistem ini juga menggunakan aplikasi pada smartphone android sebagai alert. Jika sensor mendeteksi beberapa gerakan, sensor akan mengaktifkan notifikasi di aplikasi android. Notifikasi di aplikasi android berisi 'Motion Detected check ftp: //ftp.roomsurveillance.info'. Hasil dari sistem surveilans ini berupa snapshot yang dikirimkan oleh kamera IP, dapat dilihat dan diunduh dengan mengklik link FTP. Sistem pengawasan ini dapat meningkatkan keamanan ruangan dalam kondisi realtime.
\end{abstract}

Kata Kunci: Surveillance Sistem, Motion Sensor PIR, Arduino UnoR3, Arduino Ethernet shield, IP CAM, Android Aplication

\section{PENDAHULUAN}

Keamanan menjadi fokus utama bagi setiap orang, terlebih bagi mereka yang memiliki barang berharga. Berbagai cara dilakukan untuk mencegah terjadinya aksi pencurian. Mulai dari menyimpan barang berharga di ruang rahasia, menggunakan pintu berkode, menggunakan brankas, serta menggunakan kamera pengawas.

CCTV (Closed Circuit Television) merupakan jenis kamera pengawas yang sering digunakan, karena CCTV dapat selalu merekam apapun yang terpantau dalam jangkauan dan menyimpan hasil rekamannya di DVR (Digital Video Recorder) yang terletak pada control room. Kendati demikian, bila terjadi aksi percurian, pemilik baru akan mengetahuinya setelah aksi pencurian itu terjadi karena pemilik tak dapat memantau ruangan dalam keadaan realtime. Dan hal terburuknya adalah bila si pencuri mengambil DVR dari control room, maka aksinya akan sulit dilacak karena seluruh hasil rekaman yang tersimpan akan hilang. Sebagai alternatif dari permasalahan ini, jenis kamera pengawas lain dapat digunakan yakni IP kamera.

IP kamera merupakan sebuah kamera pengawas yang terhubung langsung ke internet. Tidak membutuhkan control room untuk memantau, karena IP kamera menggunakan NVR (Network Video 
Recorder) sebagai media penyimpanan. Namun IP kamera tidak menyimpan dalam bentuk video, melainkan dalam bentuk gambar. Dengan media penyimpanan NVR, pemilik tak akan kehilangan data yang telah terekam oleh IP kamera. Selain itu, IP kamera memiliki fitur Motion Detection yang dapat mendeteksi adanya gerakan dan mengcapturenya lalu mengirimkan hasil gambarnya ke web dan dapat diakses langsung oleh si pemilik.

Pada penulisan ini, sistem keamanan akan dibuat dengan memanfaatkan fitur Motion Detection dari IP kamera. Disamping itu, sensor PIR digunakan sebagai pendeteksi gerakan akan terhubung dengan mikrokontroler Arduino Uno dan ethernet shield. Sistem ini juga memanfaatkan aplikasi pada smartphone berbasis android sebagai alert. Bila sensor PIR mendeteksi gerakan, akan muncul pemberitahuan melalui aplikasi pada smartphone android. Pemberitahuan tersebut berupa link web untuk mendownload gambar yang telah dicapture oleh Motion Detection dari IP kamera. Dengan demikian, pemilik dapat memantau ruangan dalam kondisi realtime

\section{KAJIAN PUSTAKA}

\section{Mikrokontroler Arduino}

Mikrokontroler arduino adalah pengendali mikro single board yang bersifat open source, dirancang untuk memudahkan penggunaan elektronik dalam berbagai bidang. Hardwarenya memiliki prosesor Atmel AVR dan softwarenya memiliki bahasa pemrograman sendiri.

Arduino juga merupakan platform hardware terbuka yang ditujukan kepada siapa saja yang ingin membuat peralatan elektronik interaktif berdasarkan hardware dan software yang fleksibel dan mudah digunakan. Mikrokontroler ini diprogram menggunakan bahasa pemrograman arduino yang memiliki kemiripan syntax dengan bahasa pemrograman C. Karena sifatnya yang terbuka, maka siapa saja dapat mengunduh skema hardware arduino dan membangunnya.

Arduino menggunakan keluarga mikrokontroler ATMega yang dirilis oleh Atmel sebagai basis, namun ada individu/perusahaan yang membuat clone arduino dengan menggunakan mikrokontroler lain dan tetap kompatibel dengan arduino pada level hardware. Untuk fleksibilitas, program dimasukkan melalui bootloader meskipun ada opsi untuk membypass bootloader dan menggunakan downloader untuk memprogram mikrokontroler secara langsung melalui port ISP.

Seperti Microcontroller yang banyak jenisnya, Arduino lahir dan berkembang, kemudian muncul dengan berbagai jenis. Diantaranya adalah:

\section{Arduino Uno}

Arduino Uno adalah papan sirkuit berbasis mikrokontroler ATmega328. IC (integrated circuit) ini memiliki 14 input/output digital (6 output untuk PWM), 6 analog input, resonator kristal keramik $16 \mathrm{MHz}$, Koneksi USB, soket adaptor, pin header ICSP, dan tombol reset. Hal inilah yang dibutuhkan untuk mensupport mikrokontrol secara mudah terhubung dengan kabel power USB atau kabel power supply adaptor AC ke DC atau juga battery.

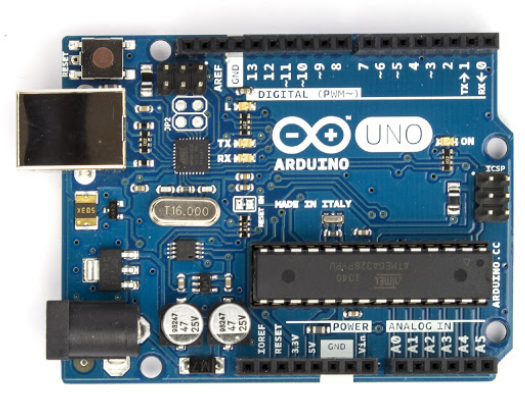

Gambar 1. Arduino Uno MainBoard

Arduino UNO R3 ATmega328berbeda dari semua board mikrokontroler diawal-awal yang tidak menggunakan chip khusus driver FTDI USB-to-serial. Sebagai penggantinya penerapan USB-to-serial adalah ATmega16U2 versi R2 (versi sebelumnya ATmega8U2). Versi Arduino Uno Rev.2 dilengkapi resistor ke 8U2 ke garis ground yang lebih mudah diberikan ke mode DFU. 
Table 1. Arduino Uno Rev.2

\begin{tabular}{ll}
\hline Microcontroller & ATmega328 \\
\hline Operating Voltage & $5 \mathrm{~V}$ \\
\hline Input Voltage (recommended) & $7-12 \mathrm{~V}$ \\
\hline Input Voltage (limits) & $6-20 \mathrm{~V}$ \\
\hline Digital I/O Pins & 14 (of which 6 provide PWM output) \\
\hline Analog Input Pins & 6 \\
\hline DC Current per I/O Pin & $40 \mathrm{~mA}$ \\
\hline DC Current for 3.3V Pin & $50 \mathrm{~mA}$ \\
\hline Flash Memory & $32 \mathrm{~KB}$ (ATmega328) of which $0.5 \mathrm{~KB}$ used \\
& by bootloader \\
\hline SRAM & $2 \mathrm{~KB}$ (ATmega328) \\
\hline EEPROM & $1 \mathrm{~KB}($ ATmega328) \\
\hline Clock Speed & $16 \mathrm{MHz}$ \\
\hline Length & $68.6 \mathrm{~mm}$ \\
\hline Width & $53.4 \mathrm{~mm}$ \\
\hline Weight & $25 \mathrm{~g}$ \\
\hline
\end{tabular}

\section{Arduino Ethernet Shield}

Arduino Ethernet Shield adalah modul yang berfungsi menghubungkan Arduino board dengan jaringan internet,karna itu berdasar pada Wiznet W5100 ethernet chip ( datasheet).

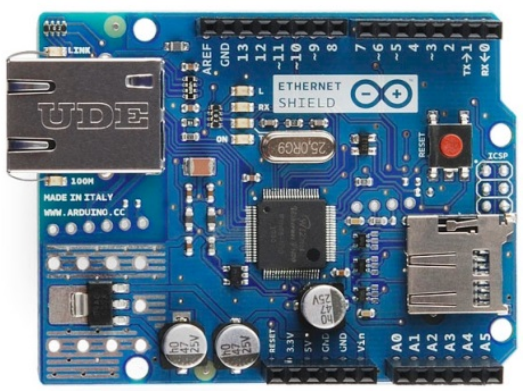

Gambar 2. Arduino Ethernet Shield

Untuk menghubungkan dan menggunakan modul hingga dapat terkoneksi internet cukup mudah, hanya membutuhkan waktu beberapa menit saja.caranya dengan memasangkan modul tersebut di atas Arduino bord, sambungkan dengan kabel network RJ45, ikuti tutorial pemogramannya (menggunakan pustaka Ethernet yang sudah tersedia di paket perangkat lunak Arduino IDE), dan Arduino Anda siap dikendalikan lewat internet.

Dalam arduino ethernet sendiri terdapat slot mikro SD yang berbungsi sebagai tempat penyimpanan file sedangkan untuk mengakses mikro SD card mengunakan library SD , untuk jenis arduino board yang bisa di pasangkan dengan ethernet shield W5100 yaitu arduino uno dan mega.

\section{IP Kamera}

IP kamera adalah jenis kamera video digital yang biasa digunakan untuk pemantauan keamanan dan dapat mengirim dan menerima data melalui jaringan komputer dan internet. Walaupun webcam juga dapat melakukan hal ini namun istilah " IP Kamera" atau "Network Kamera" biasanya hanya digunakan untuk sistem pengawasan keamanan. IP Kamera pertama digunakan pertama kali pada tahun 1996.

Jenis-jenis IP kamera :

1. Fix Ip kamera.

2. Dome IP Kamera.

3. PTZ (pan, tilt, zoom). 


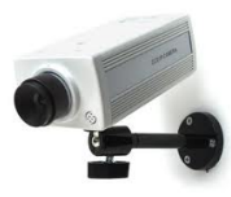

FIX IP CAMERA

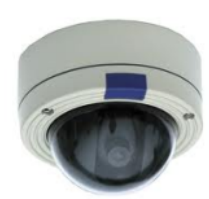

DOME IP CAMERA

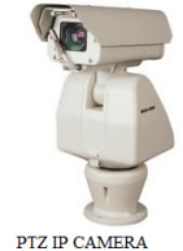

PTZ IP CAMERA

Gambar 3. Bentuk Fisik CCTV (IP Camera)

Pada dasarnya menghubungkan IP Kamera ke jaringan tdk jauh berbeda dgn alat2 yg terhubung dgn jaringan komputer.Yaitu yg pertama ia harus punya alamat IP. Cara memberi (setting) alamat IP berbeda2 untuk tiap merk. Caranya bisa dilihat pada buku manualnya masing-masing.

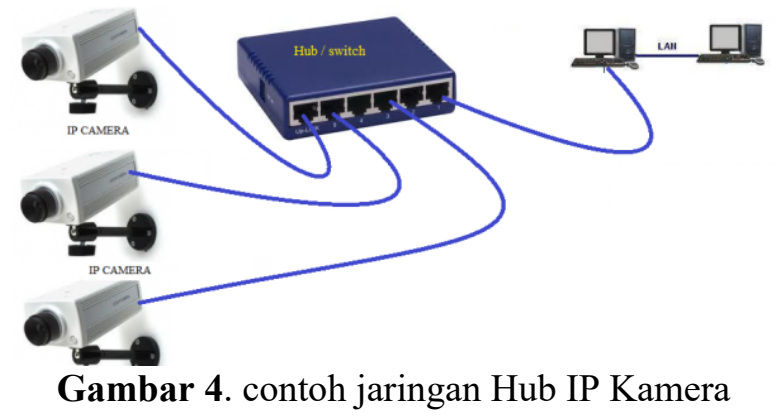

Cara Mengakses IP Kamera yg paling mudah dengan web browser semacem mozilla atau IE atau google crome. Cukup dgn mengetik alamat IP kamera di web rowser maka akan muncul tampilan atau menu sederhana untuk mengaktifkan IP Kamera.

\section{Android}

Android adalah sistem operasi berbasis Linux yang dirancang untuk perangkat bergerak layar sentuh seperti telepon pintar dan komputer tablet. Android awalnya dikembangkan oleh Android, Inc., dengan dukungan finansial dari Google, yang kemudian membelinya pada tahun 2005. Sistem operasi ini dirilis secara resmi pada tahun 2007, bersamaan dengan didirikannya Open Handset Alliance, konsorsium dari perusahaanperusahaan perangkat keras, perangkat lunak, dan telekomunikasi yang bertujuan untuk memajukan standar terbuka perangkat seluler. Ponsel Android pertama mulai dijual pada bulan Oktober 2008.

Antarmuka pengguna Android umumnya berupa manipulasi langsung, menggunakan gerakan sentuh yang serupa dengan tindakan nyata, misalnya menggeser, mengetuk, dan mencubit untuk memanipulasi objek di layar, serta papan ketik virtualuntuk menulis teks. Selain perangkat layar sentuh, Google juga telah mengembangkan Android TV untuk televisi, Android Auto untuk mobil, dan Android Wear untuk jam tangan, masing-masingnya memiliki antarmuka pengguna yang berbeda. Varian Android juga digunakan pada komputer jinjing, konsol permainan, kamera digitAVRal, dan peralatan elektronik lainnya.

Android adalah sistem operasi dengan sumber terbuka, dan Google merilis kodenya di bawah Lisensi Apache. Kode dengan sumber terbuka dan lisensi perizinan pada Android memungkinkan perangkat lunak untuk dimodifikasi secara bebas dan didistribusikan oleh para pembuat perangkat, operator nirkabel, dan pengembang aplikasi. Selain itu, Android memiliki sejumlah besar komunitas pengembang aplikasi (apps) yang memperluas fungsionalitas perangkat, umumnya ditulis dalam versi kustomisasi bahasa pemrograman Java. Pada bulan Oktober 2013, ada lebih dari satu juta aplikasi yang tersedia untuk Android, dan sekitar 50 miliar aplikasi telah diunduh dari Google Play, toko aplikasi utama Android. Sebuah survei pada bulan April-Mei 2013 menemukan bahwa Android adalah platform paling populer bagi para pengembang, digunakan oleh 71\% pengembang aplikasi bergerak. Di Google I/O 2014, Google melaporkan terdapat lebih dari satu miliar pengguna aktif bulanan Android, meningkat dari 583 juta pada bulan Juni 2013.

\section{Sensor PIR}

Sensor gerak PIR (Passive Infra Red) adalah sensor yang berfungsi untuk pendeteksi gerakan yang bekerja dengan cara mendeteksi adanya perbedaan/perubahan suhu sekarang dan sebelumnya. Sensor gerak menggunakan modul pir sangat simpel dan mudah diaplikasikan karena Modul PIR hanya membutuhkan tegangan input DC 5V cukup efektif untuk mendeteksi gerakan hingga jarak 5 meter. Ketika tidak mendeteksi 
gerakan, keluaran modul adalah LOW. Dan ketika mendeteksi adanya gerakan, maka keluaran akan berubah menjadi HIGH. Adapun lebar pulsa HIGH adalah $\pm 0,5$ detik. Sensitifitas Modul PIR yang mampu mendeteksi adanya gerakan pada jarak 5 meter memungkinkan untuk membuat suatu alat pendeteksi gerak dengan keberhasilan lebih besar.

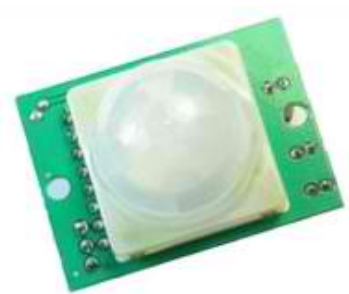

Gambar 5. Bentuk Sensor Gerak PIR (Passive Infra Red)

Dengan output yang hanya memberikan 2 logika High dan Low ini dapat dibuat aplikasi sensor gerak yang berfariatif. Misal langsung aplikasikan pada alarm, cukup membuat rangkaian driver untuk mengaktifkan alarm tersebut. Atau misal ingin digunakan untuk mengaktifkan lampu, maka tinggal di buat driver untuk memberikan sumber tegangan ke lampu. Modul sensor gerak PIR memiliki output yang langsung bbisa di hubungkan dengan komponen digital TTL atau CMOS dan juga dapat lansung dihubungkan ke mikrokontroler.

Efektifitas pendeteksian gerakan menggunakan sensor gerak ini dipengaruhi oleh faktor penempatan sensor gerak PIR tersebut. Posisi sensor gerak harus diletakan pada lokasi yang dapat membaca semua gerakan yang ada dalam ruangan atau daerah yang dimonitor oleh sensor gerak PIR.

\section{METODE}

\section{Blok sistem}

Pada bagian ini akan dibahas system pemantauan yang dikhususkan untuk ruangan kosong dengan brankas di dalamnya. Sistem ini menggunakan IP kamera sebagai input utama, terdapat fitur Motion Detection pada IP kamera yang dapat mendeteksi adanya gerakan. Bila fitur tersebut mendeteksi gerakan, IP kamera akan meng-capture gambar gerakannya dan mengirimkan gambar itu ke web pemilik menggunakan FTP (File Transfer Protocol). Agar pemilik dapat mengetahui bila IP kamera mengirim gambar ke web, system ini juga menggunakan sensor PIR sebagai pendeteksi gerakan. Setiap mendeteksi gerakan, sensor PIR akan memberikan logika "1" ke mikrokontroler arduino yang telah terkoneksi ke Ethernet shield, lalu Ethernet shield akan mengirim informasi ke aplikasi android berupa pemberitahuan bahwa telah terjadi gerakan dan memberikan link web supaya pemilik dapat mendownload gambarnya.

Berdasarkan fungsi dari system pemantauan, dapat dibagi menjadi beberapa blok. Diagram blok sitem dapat dilihat pada Gambar 6.

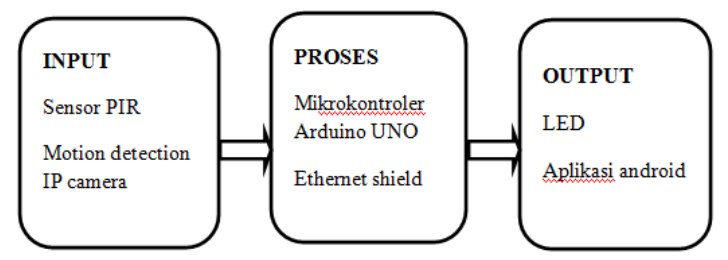

Gambar 6. Diagram Blok Sistem

System pemantauan ini menggunakan sensor PIR dan fitur Motion Detection pada IP kamera sebagai input. Sinyal input akan diproses oleh ethernet shield yang terhubung dengan mikrokontroler arduino, kemudian sinyal output akan dikirim ke blok output. Blok output terdiri dari led dan notifikasi melalui aplikasi android.

\section{Rangkaian Seluruh Sistem}

Blok input, proses, dan output telah disatukan dalam keseluruhan rangkaian dari sistem pemantauan ini dan dapat terlihat pada Gambar 7. 


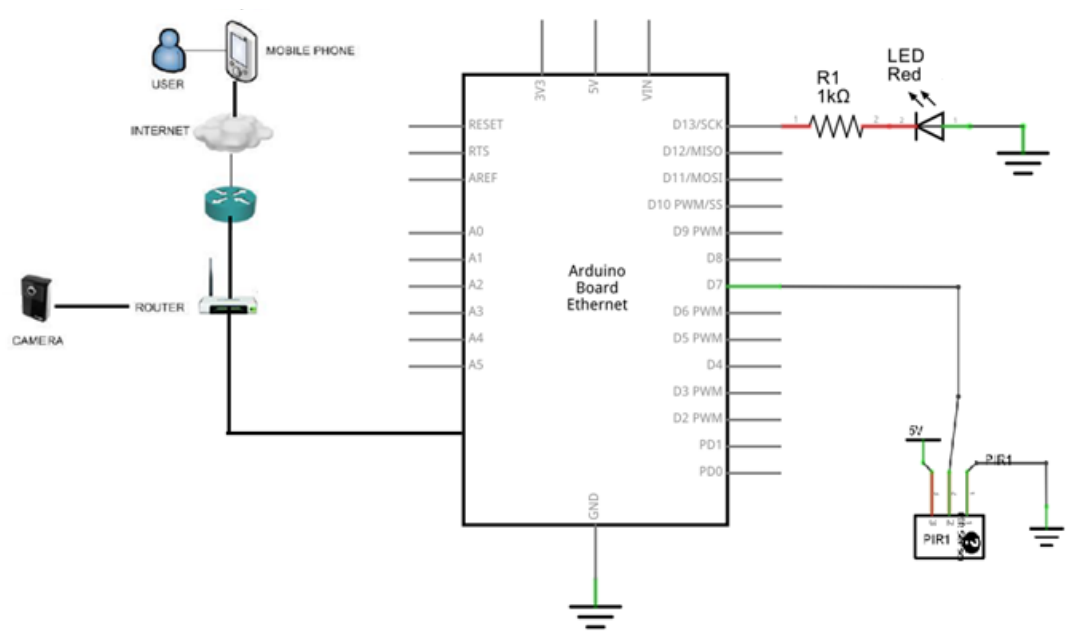

Gambar 7. Rangkaian Seluruh Sistem

\section{Desain Software}

Program dimulai dengan inisialisasi. Berikutnya program akan membaca sensor PIR, bila sensor PIR mendeteksi gerakan itu berarti sensor PIR memberikan sinyal input ke mikrokontroler untuk diproses dan selanjutnya mikrokontroler akan memberikan logika 1 (high) ke LED maka LED akan menyala dan mikrokontroler juga mengirimkan informasi ke aplikasi android melalui router. Notifikasi yang akan muncul di aplikasi android berupa kalimat 'Motion Detected, lets check http://surveillancesys.info/belindaadp/'. Di saat bersamaan ketika sensor PIR mendeteksi gerakan, IP camera juga mendeteksi gerakan dan meng-capture gambar lalu mengirimkannya ke web pengguna. Bila sensor PIR tidak mendeteksi gerakan, maka mikrokontroler akan memberikan logika 0 (low) pada LED sehingga LED tidak menyala dan program akan membaca ulang kondisi sensor PIR.

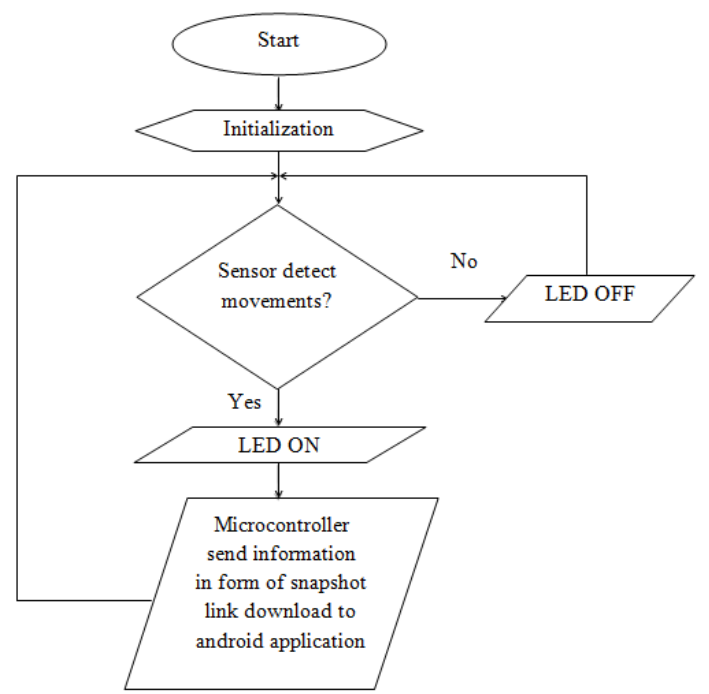

Gambar 8. Flowchart Program

\section{HASIL DAN PEMBAHASAN}

\section{Hasil Pengujian Blok Input}

Pengujian pada blok input terdiri dari pengujian sensor PIR dan IP kamera. Pengujian pada sensor PIR dilakukan dengan cara melewatkan suatu objek di depan sensor PIR. Sedangkan pengujian pada IP kamera dilakukan dengan cara menyeting pengaturan pada IP kamera sehingga IP kamera dapat bekerja sesuai dengan tujuan dari system.

\section{Hasil Pengujian pada Sensor PIR}


Pengujian dilakukan dengan melewatkan atau menggerakkan suatu objek didepan sensor PIR. Pengujian ini menentukan jarak maksimum dari objek yang dapat terdeteksi oleh sensor. Objek yang digunakan dalam pengujian ini adalah benda hidup dan benda mati. Benda hidupnya adalah manusia dan benda mati yang digunakan adalah kursi. Rangkaian yang diuji terlihat pada Gambar 9.

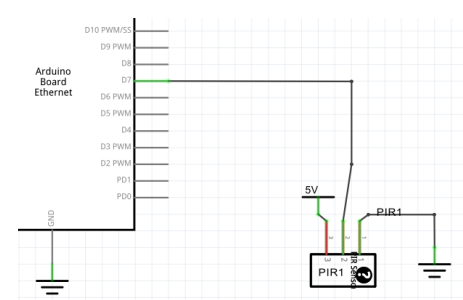

Gambar 9. Rangkaian Sensor PIR

Sensor PIR akan memberikan data atau informasi kepada input pin mikrokontroler Arduino yang nantinya akan diproses oleh Ethernet shield dan outputnya dikirim ke aplikasi android untuk memunculkan notifikasi pada smartphone.

Tabel 2. Hasil Pengujian Sensor PIR

\begin{tabular}{ccccc}
\hline Jarak $(\mathrm{cm})$ & Objek & Indikator & Keterangan & PIR Vout $(\mathrm{V})$ \\
\hline \multirow{2}{*}{30} & Manusia & LED menyala & Terdeteksi & 3.3 \\
\cline { 2 - 5 } & Kursi & LED menyala & Terdeteksi & 3.3 \\
\hline \multirow{2}{*}{60} & Manusia & LED menyala & Terdeteksi & 3.3 \\
\cline { 2 - 5 } & Kursi & LED menyala & Terdeteksi & 3.3 \\
\hline \multirow{2}{*}{120} & Manusia & LED menyala & Terdeteksi & 3.3 \\
\cline { 2 - 5 } & Kursi & LED menyala & Terdeteksi & 3.3 \\
\hline \multirow{2}{*}{240} & Manusia & LED menyala & Terdeteksi & 3.3 \\
\cline { 2 - 5 } & Kursi & LED menyala & Terdeteksi & 3.3 \\
\hline \multirow{2}{*}{480} & Manusia & LED menyala & Terdeteksi & 3.3 \\
\cline { 2 - 5 } & Kursi & LED menyala & Terdeteksi & 3.3 \\
\hline \multirow{2}{*}{500} & Manusia & LED tidak menyala & Tidak terdeteksi & 0 \\
\cline { 2 - 5 } & Kursi & LED tidak menyala & Tidak terdeteksi & 0 \\
\hline
\end{tabular}

Berdasarkan hasil pengujian pada sensor PIR pada Tabel 2 dengan melewatkan objek di hadapan sensor, mampu mendeteksi gerakan objek dari jarak $30 \mathrm{~cm}$ hingga $480 \mathrm{~cm}$ dengan indikasi menyalanya LED. Sedangkan pada jarak $500 \mathrm{~cm}$ keatas, sensor PIR tidak dapat mendeteksi gerakan objek sehingga LED tidak menyala. Berdasarkan datasheet PIR HC-SR501, tegangan keluaran yang dihasilkan oleh sensor PIR ketika sensor mendeteksi objek adalah $3.3 \mathrm{~V}$.

\section{Hasil Pengujian pada IP Kamera}

Pengujian pada IP kamera dilakukan dengan cara mengatur pengaturan IP kamera. Pengaturan yang diatur adalah pada motion detection agar IP kamera dapat mendeteksi gerakan dan meng-capture gambar.

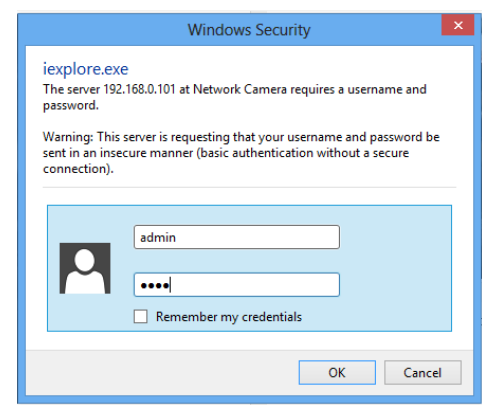

Gambar 10. Login Web IP Kamera 
Seperti yang terlihat pada Gambar 10, untuk mengatur pengaturan IP kamera, langkah pertama yang dilakukan adalah login ke web IP kamera dengan cara mengetik 192.168.0.101 pada internet explorer kemudian masukan username dan password, username dan password tertera pada bagian belakang IP kamera.

Setelah login ke web IP kamera, terlihat beranda dari web IP kamera dan terdapat beberapa menu. Beranda pada web IP kamera terlihat pada Gambar 11.

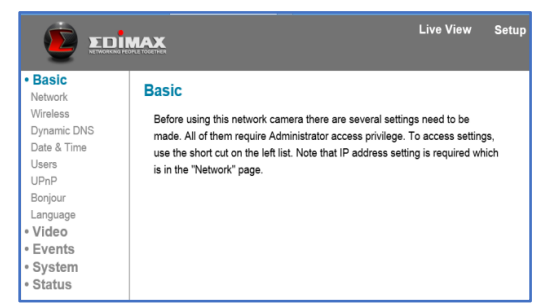

Gambar 11. Beranda Web IP Kamera

Pada beranda web IP kamera terdapat beberapa menu, yaitu Basic, Video, Events, System, dan status. Karena pada system keamanan ini IP kamera digunakan sebagai pendeteksi gerakan, maka menu yang diatur adalah menu Events. Pada menu Events, terdapat sub menu yakni Motion Detection. Motion Detection adalah fitur pada IP kamera yang mampu meng-capture gambar bila ada gerakan yang terjadi di hadapan IP kamera.

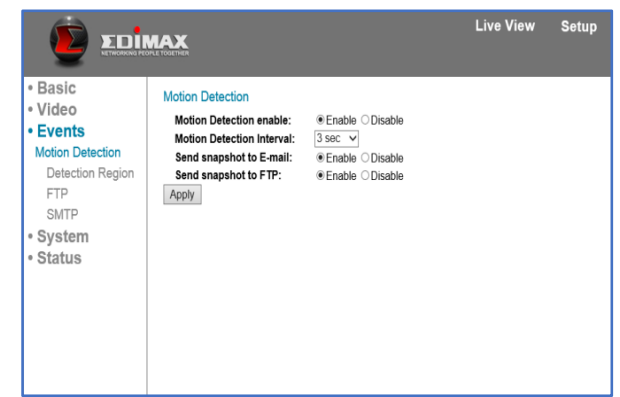

Gambar 12. Pengaturan pada Sub-Menu Motion Detection

Pada Gambar 12 terlihat pengaturan pada sub-menu Moion Detection. Pengaturan pertama yang dilakukan pada fitur Motion Detection adalah mengaktifkan Motion Detection, kemudian interval untuk meng-capture gambar juga diatur 3 detik, berikutnya pengaturan untuk mengirim snapshot dapat dipilih untuk dikirim ke emaik dan FTP atau hanya salah satunya. Sub-menu pada menu Event yang berikutnya diatur adalah FTP (File Transfer Protocol). Pengaturan ini dimaksudkan untuk mengirim snapshot yang telah di-capture oleh IP kamera ke website user.

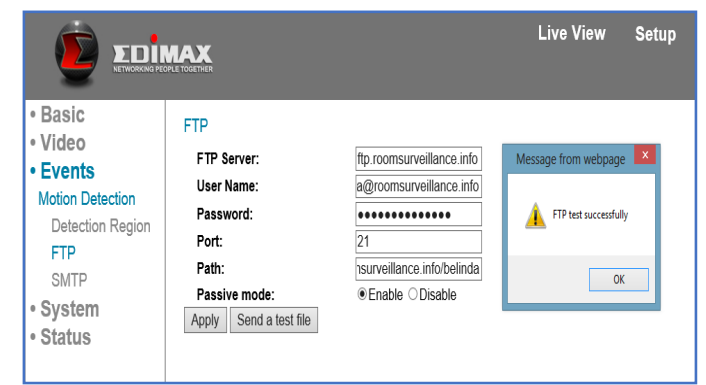

Gambar 13. Pengaturan FTP

Untuk mengaktifkan FTP, langkah pertama yang dilakukan adalah mengisi FTP Server. FTP Server adalah alamat FTP pada website user agar snapshot dapat terkirim dengan benar. Kemudian masukkan username dan password, untuk username dan password diatur di CPanel pada website user. Port pada pengaturan FTP telah ditetapkan, yakni port 21. Selanjutnya masukkan Path atau direktori untuk menyimpan hasil snapshot yang telah dikirim. Untuk Passive Mode telah ditetapkan sama seperta port. Langkah terakhir adalah mengklik Apply dan Send a test file untuk mengetahui apakah pengaturan yang telah dimasukkan benar 
atau tidak. Pada Gambar 13 terlihat bahwa FTP test successfully, itu berarti FTP server yang dimasukkan pada pengaturan FTP sudah benar dan website pengguna siap menerima snapshot yang dikirim oleh IP kamera.

\section{Hasil Pengujian Blok Proses}

Pengujian blok proses merupakan pengujian pada mikrokontroler Arduino. Pengujian dilakukan dengan cara menghitung tegangan pada port mikrokontroler ketika system aktif.

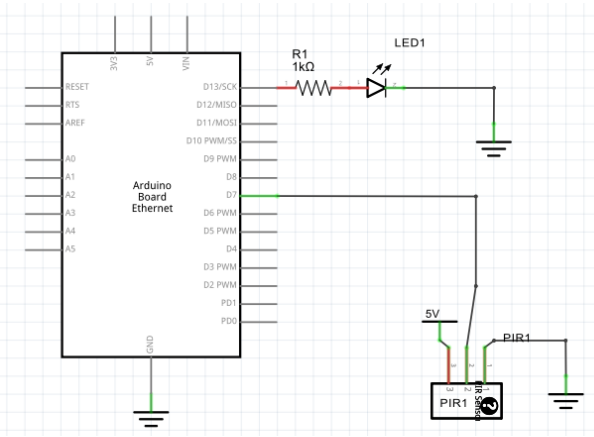

Gambar 14. Rangkaian Blok Proses

Seperti yang terlihat pada Gambar 4.6 komponen yang diuji dalam blok proses adalah sensor PIR dan LED. Tegangan keluaran dari kedua komponen diukur menggunakan multimeter.

Tabel 3. Hasil Pengujian Blok Proses

\begin{tabular}{ccccc}
\hline No & Komponen & Port & Tegangan (Volt) & Keterangan \\
\hline 1 & Sensor PIR & D7 & 3.3 & Mendeteksi gerakan objek \\
\hline 2 & LED & D13 & 4.91 & Menyala ketika sensor mendeteksi gerakan objek \\
\hline
\end{tabular}

Berdasarkan hasil pengujian blok proses pada Tabel 4.2, tegangan output yang dihasilkan oleh sensor PIR ketika mendeteksi gerakan adalah $3.3 \mathrm{~V}$ dan tegangan output yang dihasilkan oleh LED ketika menyala adalah $4.91 \mathrm{~V}$.

\section{Hasil Pengujian Blok Output}

Pengujian blok output terdiri dari 2 (dua) bagian, yaitu LED dan aplikasi android. Pengujian pada blok output dilakukan dengan cara menghitung tegangan LED ketika menyala karena sensor mendeteksi gerakan. Di samping itu, pengujian juga dilakukan pada aplikasi android dengan cara mengatur aplikasi agar dapat menerima notifikasi dari mikrokontroler ketika sensor PIR mendeteksi gerakan dan pengujian ini menunjukkan tampilan dari aplikasi android ketika terdapat notifikasi.

\section{Hasil Pengujian pada LED}

Pengujian pada LED dilakukan dengan cara mengukur tegangan keluaran (V) pada LED ketika menyala. Rangkaian yang diuji terlihat pada Gambar 15.

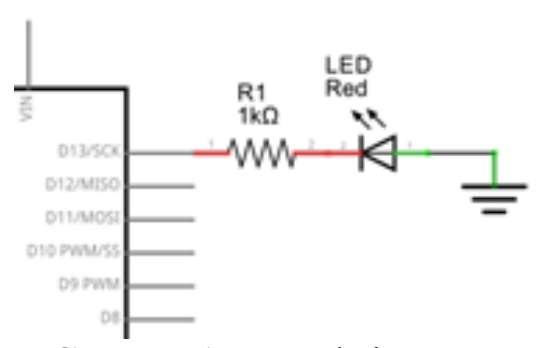

Gambar 15. Rangkaian LED

Dalam system pemantauan ini, LED digunakan sebagai indicator dari sensor PIR. Ketika sensor PIR mendeteksi gerakan, LED akan menyala. Pada pengujian LED, tegangan keluaran dari LED diukur menggunakan multimeter. Hasil pengujian LED dapat dilihat di Tabel 4. 
JTI | Volume 1, Issue 1 (2021) | 1-12

Tabel 4. Hasil Pengujian pada LED

Penjelasan:

\begin{tabular}{cccc}
\hline No & Sensor PIR & Kondisi LED & Tegangan (Volt) \\
\hline 1 & 0 & Tidak menyala & 0 \\
\hline 2 & 1 & Menyala & 4.91 \\
\hline
\end{tabular}

$0 \quad=$ Tidak mendeteksi gerakan objek

$1=$ Mendeteksi gerakan objek V.

Berdasarkan hasil pengujian LED, tegangan output yang dihasilkan oleh LED ketika menyala adalah 4.91

\section{Hasil Pengujian pada Aplikasi Android}

Pada apikasi android, pengujian dilakukan dengan cara men-generate key number untuk dimasukan ke program arduino sehingga aplikasi android terhubung dengan mikrokontroler dan aplikasi android dapat memunculkan notifikasi ketika sensor PIR mendeteksi gerakan. Hasil pengujian pada aplikasi android dapat dilihat pada Gambar 16.

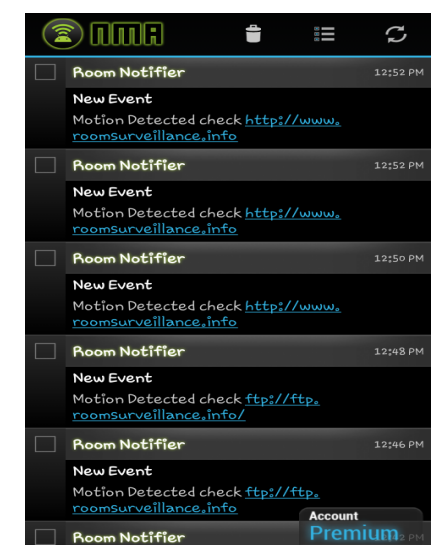

Gambar 16. Aplikasi Android

Berdasarkan hasil pengujian pada aplikasi android, terlihat beberapa notifikasi muncul yang bertuliskan 'Motion Detected check ftp://ftp.roomsurveillance.info'. Notifikasi tersebut akan muncul di aplikasi android setiap sensor PIR mendeteksi gerakan. Setelah notifikasi muncul, pengguna dapat mengklik link yang terdapat pada aplikasi android tersebut untuk mendownload snapshot yang telah dikirim oleh IP kamera.

\section{Hasil dari Implementasi Sistem}

Pengujian pada blok input, proses, dan output telah dilakukan, berikutnya adalah mengimplementasikan semua pengujian dalam bentuk gambar mulai dari system belum aktif hingga saat aplikasi menerima notifikasi dari mikrokontroler dan mendownload gambar kondisi ruangan.

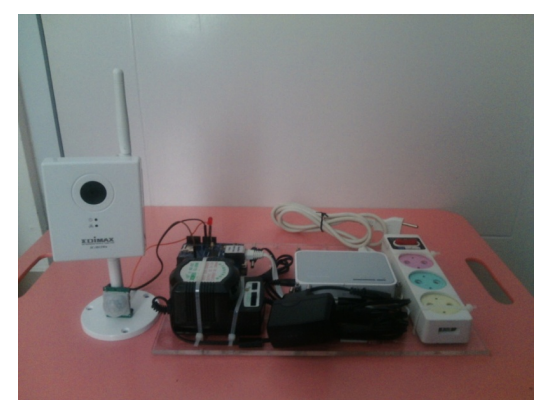

Gambar 17. Sistem Sebelum Aktif

Implemenasi system sebelum aktif titunjukkan pada Gambar 4.9. dalam gambar tersebut terdapat semua komponen yang digunakan pada system pemantauan ini, antara lain IP kamera, sensor PIR, mikrokontroler Arduino beserta Ethernet shield, LED beserta resistornya, adaptor, switch hub, dan kabel roll. 
Untuk mengaktifkan system, sambungkan adaptor mikrokontroler, switch hub, dan IP kameka ke kabel roll yang telah disiapkan pada system. Setelah system aktif, LED pada IP kamera, adaptor, dan switch hub akan menyala.

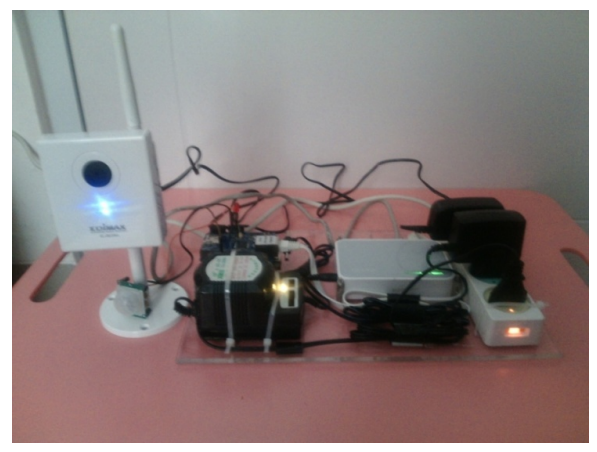

Gambar 18. Sistem Setelah Aktif

Pada Gambar 18 terlihat bahwa system pemantauan telah aktif ditandai dengan menyalanya LED pada kabel roll, switch hub, adaptor, mikrokontroler, dan IP kamera. Ketika system telah aktif, sensor PIR dapat diuji dengan menggerakkan subjek di hadapan sensor. Kemudian muncul lah notifikasi pada aplikasi android. Disaat yang bersamaan, IP kamera juga mendeteksi gerakan dan mengirim snapshot ke website. Tampilan aplikasi android terlihat pada Gambar 19.

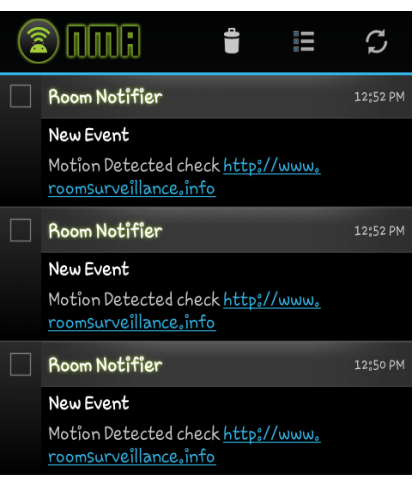

Gambar 19. Tampilan Aplikasi Android

Pada aplikasi android, notifikasinya bertuliskan 'Motion Detected check ftp://ftp.roomsurveillance.info'. Link FTP tersebut merukapan link untuk melihat dan mendownload hasil gambar yang di-capture oleh IP kamera. Untuk melihat snapshot yang dikirim oleh IP kamera, link FTP pada aplikasi android harus diklik. Ketika link tersebut diklik, muncul semua gambar yang telah di-capture dan dikirim oleh IP kamera.

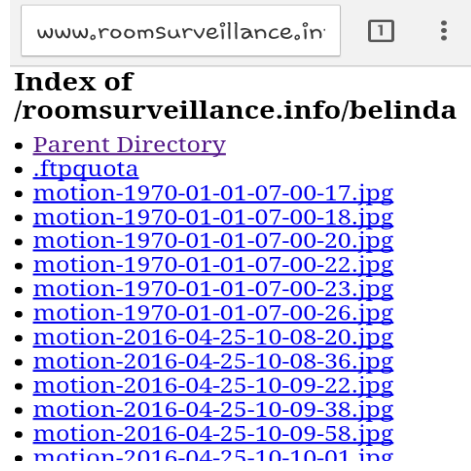

Gambar 20. Tampilan Website Pengguna

Seperti yang terlihat pada Gambar 20 link snapshot yang terdapat pada direktori website pengguna urut berdasarkan waktu pengambilan gambar. Maka, gambar terbaru yang dikirim oleh IP kamera terdapat di urutan terbawah. Ketika link gambar di-klik, muncul lah gambar yang telah di-capture oleh IP kamera dan gambar siap untuk di-download. 


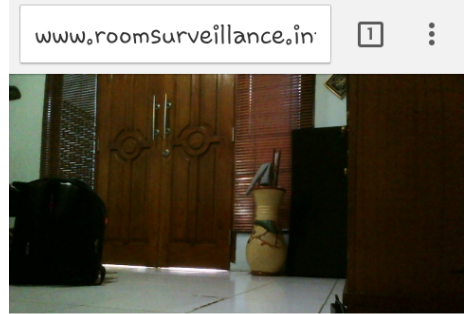

Gambar 21. Snapshot pada Website Pengguna

Hasil snapshot yang dicapture dan dikirim oleh IP kamera ke website pengguna terlihat pada Gambar 21 . Snaphot yang telah dikirim dan terdapat pada direktori website pengguna urut berdasarkan waktu pengambilan gambar, jadi untuk melihat snapshot terbaru harus scroll ke bagian bawah direktorti. Snapshot yang ada pada direktori dapat didownload ataupun hanya sekedar dilihat.

\section{KESIMPLAN DAN SARAN}

Berdasarkan hasil pengujian perangkat dapat disimpulkan sebagai berikut:

1) System ini didesain untuk meningkatkan keamanan pada ruang yang berisi barang berharga dengan menggunakan IP kamera sebagai tool utama dan sensor PIR sebagai pendeteksi gerakan.

2) Pengguna dapat menerima informasi tentang keamanan ruangan dalam kondisi realtime melalui aplikasi android.

3) Jarak maksimum sensor PIR untuk mendeteksi objek adalah $480 \mathrm{~cm}$.

4) Pada system pemantauan ini, IP kamera mengirimkan hasil pantauan gerakan dalam bentuk snapshot yang kemudian dikirim ke website pengguna.

5) System pemantauan ini tidak dapat menggunakan router seluler karena kecepatan ransfer datanya lambat.

\section{REFERENCES}

Anonymous., -, Android (Operating System), https:// en.wikipedia.org/wiki/ Android_(operating_system)

Anonymous., -, Arduino Board Uno, http://arduino.cc/en/Main/arduinoBoardUno,

[Anonymous., -, Arduino Ethernet Shield, http://arduino.cc/en/Main/ArduinoEthernetShield,

Anonymous., -, LED Symbol, http://en.wikipedia.org/wiki/File :LED_symbol.svg,

Anonymous., 2005, The Linux Information Project, http://www.linfo.org/router.html,

Clewisperry., 2012, Notify My Android Door Alerts, http://www.instructables.com/id/ Notify-My-Android/,

DatasheetPDF.com, 2014, HC- SR501 Datasheet, http://www.datasheetspdf.com/PDF/HC-SR501/775434/1,

Elkay, 2012, Passive Infra Red (PIR) Sensors. How do they work?, http://www.elkay.co.uk/ newsdet ail.asp?id=334,. 